\title{
A New Approach to Land-Use Structure: Patch Perimeter Metrics as a Spatial Analysis Tool
}

\author{
Ilaria Zambon ${ }^{1}{ }^{(\mathbb{D}}$, Pere Serra ${ }^{2}$ (D), Silvia Pili ${ }^{3}$, Vincenzo Bernardini ${ }^{4}$ (), Carlotta Ferrara ${ }^{4}$ \\ and Luca Salvati ${ }^{4, *}$ \\ 1 Department of Agricultural and Forestry Sciences (DAFNE), Tuscia University, Via San Camillo de Lellis, 5, \\ I-01100 Viterbo, Italy; ilaria.zambon@unitus.it \\ 2 Department of Geography, Autonomous University of Barcelona, Building B, Campus UAB, \\ ES-08193 Bellaterra (Cerdanyola del Vallès), Barcelona, Spain; pere.serra@uab.cat \\ 3 Department of Architecture and Project, Sapienza University of Rome, Via Flaminia 369, I-00196 Rome, Italy; \\ silvia.pili@uniroma1.it \\ 4 Council for Agricultural Research and Economics (CREA), Viale S. Margherita 80, I-52100 Arezzo, Italy; \\ vincenzo.bernardini@crea.gov.it (V.B.); carlottaferrara@gmail.com (C.F.) \\ * Correspondence: luca.salvati@crea.gov.it
}

Received: 1 June 2018; Accepted: 22 June 2018; Published: 24 June 2018

\begin{abstract}
This work introduces a new class of landscape metrics characterizing basic features of patch perimeters. Specific computation on patch perimeters was carried out on fine-grained land-use maps with the aim to characterize spatial patterns of neighbor patches, evidencing contact points and perimeter length between two (or more) land-use types. A detailed set of class and landscape metrics were derived from such analysis. This approach is complementary to classical landscape metrics and proved to be particularly useful to characterize complex, fragmented landscapes profiling metropolitan regions based on integrated evaluations of their structural (landscape) and functional (land-use) organization. A multivariate analysis was run to characterize distinctive spatial patterns of the selected metrics in four metropolitan regions of southern Europe reflecting different morphological configurations (Barcelona: compact, polycentric; Lisbon: dispersed, mono-centric; Rome: dispersed, polycentric; and Athens: compact, mono-centric). Perimeter metrics assumed different values for each investigated land-use type, with peculiar characteristics associated to each city. Land-use types assessing residential, discontinuous urban patches were associated to particularly high values of perimeter metrics, possibly indicating patch fragmentation, spatially-associated distribution of land-use types and landscape complexity. Multivariate analysis indicates substantial differences among cities, reflecting the range of morphological configurations described above (from compact mono-centric to dispersed polycentric) and suggesting that urban expansion is accompanied with multiple modifications in the use of the surrounding non-urban land. The computational approach proposed in this study and based on spatially-explicit metrics of landscape configuration and proximity may reflect latent changes in local socio-spatial structures. Our results demonstrate that scattered urban expansion determines a polarization in suburban areas with highly fragmented and more homogeneous landscapes, respectively, associated with mixed cropland and forest systems.
\end{abstract}

Keywords: spatial analysis; boundaries; perimeters; socioeconomic disparities; landscape; Mediterranean Europe

\section{Introduction}

Urban growth has increasingly shaped the spatial relationship among land-use classes along metropolitan gradients [1,2]. Urbanization-driven socioeconomic transformations have determined an 
increased fragmentation of rural landscapes, resulting in mixed and heterogeneous fringe districts typical of medium-large metropolitan regions [3-8]. Agricultural and forest land are envisioned as fundamental land-use classes: (i) buffering relict, non-urban fringe land from unregulated urban expansion; (ii) preserving fertile land from real estate speculation; and (iii) assuring ecosystem stability and provision of key ecological services under increasing anthropogenic pressure [9-12].

Recent land-use and land cover transformations are associated with different socioeconomic factors, which affect differently the spatial configuration, hierarchy and composition of landscapes negatively impacting ecosystem functioning and socio-environmental systems at large [13-16]. Results of these processes are the fragmented, mixed and ecologically-fragile landscapes, which are typically observed in metropolitan regions of advanced countries [17,18]. Mixed and fragmented landscapes are often combined with a greater social fragility of fringe districts [14,19], causing an unsustainable development leading to spatially-unbalanced economic development in the long run $[4,13,17,20,21]$.

While landscape structure and configuration in Europe have been largely investigated from multiple perspectives [22-25], changes in the spatial relationship among land-uses-considered a process at the base of landscape modifications-have been explored occasionally [3]. Approaches based on a "landscape ecology" thinking were particularly common, proposing small- and large-scale analysis of landscape structure and configurations over time. Such approaches focused on a comprehensive analysis of patch size and shape, using multiple indexes (i.e., metrics) derived from (or inspired by) computational spatial analysis, complexity theory, entropy notion and fractal thinking. The analysis proposed in this work contributes originally to this issue by computing on individual patches and identifying the spatial relationships among land-use types through the analysis of patch boundaries and contact points. In other words, this study moves from a traditional landscape ecology approach grounded on patch size and shape metrics towards a more refined approach focusing on land-use spatial patterns and neighboring regimes, reconnecting a structural analysis of landscape with a functional analysis based on an explicit characterization of land-use and land cover categories.

Spatially-explicit theories based on a quantitative analysis of contact elements are common in physical and ecological science [26,27]. Physical boundaries can designate unambiguous limits of homogeneous areas/districts and land-use categories (e.g., urban and rural) [20,28]. In spatial planning and urban studies, boundaries are considered the operational element separating different areas and land-use types [29]. At the same time, borders have been frequently reconnected with social issues, e.g., diversity, segregation, and local neighborhoods [30-34]; more recent studies conceptualize the "boundary" notion in governance issues as related to landscape services [35,36]. Although patch perimeter has been used as a benchmark in spatial studies [37-40], literature on contact theory using landscape patches as elementary analysis' units and bearing in mind indicators that quantify properties and attributes of their boundaries (shared among different land-use) is relatively restricted [41,42]. While being still poorly understood, the role of boundaries is decisive when characterizing metropolitan forms and functions.

Following spatial planning and governance of metropolitan regions, boundaries assumed jurisdictional, administrative, geographical and socioeconomic meanings [43-45], such as for participating government [46], or are merely "political borders" [47,48]. Consequently, boundaries impact (and are in turn influenced by) socio-environmental issues related to local communities, regional economic structures and the related land-use [26,49]. In this regard, urban morphology is a specific form of built-up patches with specific boundaries, reflecting a (more or less convoluted) perimeter for each land-use type, useful for calculating, e.g., its degree of irregularity based on fractal dimension [41]. Since spatial planning usually manages local contexts according to an integral zoning approach, the functions of each urban patch/area may clearly emerge by considering its perimeter and, therefore, the contact system with neighboring patches.

Based on these premises, this study provides an original approach to a joint structural and functional landscape analysis, introducing a new class of landscape metrics assessing basic features of 
patch perimeters. Specific computation on patch perimeters was carried out on fine-grained land-use maps covering homogeneously the European continent with the aim to characterize spatial patterns of neighbor patches, evidencing contact points and perimeter length between two (or more) land-use types. A detailed set of class and landscape metrics were derived from such analysis. This approach appears complementary to classical landscape metrics and proved to be particularly useful to characterize complex, fragmented landscapes profiling metropolitan regions based on integrated evaluations of their structural (landscape) and functional (land-use) configuration. Spatial diversity was evaluated using the Shannon index applied to the composition of landscape bordering each patch.

A multivariate analysis was run to characterize distinctive spatial patterns of the selected metrics in four metropolitan regions of southern Europe that reflect different morphological configurations (Barcelona: compact, polycentric; Lisbon: dispersed, monocentric; Rome: dispersed, polycentric; and Athens: compact, monocentric). Results of this work will complement studies grounded on a classical landscape ecology approach (i.e., based on landscape metrics) with a functional analysis of land-use types assessing spatial neighboring patters. Our findings constitute a knowledge base advancing integration of urban studies, landscape ecology and spatial science, offering relevant suggestions to renewed practices of sustainable management of fringe land in metropolitan regions.

\section{Methods}

\subsection{Study Area}

Four large metropolitan regions in southern Europe-three of which are capital cities-were considered in this study: Lisbon (Portugal), Barcelona (Spain), Rome (Italy), and Athens (Greece). For each city, the investigated area corresponds to the related "Urban Atlas" region. "Urban Atlas" is the major initiative dealing with sprawl monitoring all over Europe and represents an information tool for both assessment and urban policy analysis [50]. According to Urban Atlas initiative, the boundaries of metropolitan regions were identified based on a comprehensive analysis of commuting patterns, reflecting central and peripheral locations in each city. Spatial domains defined according to Urban Atlas allow reliable comparisons on population, land-use and other key variables and are homogeneous with relevant statistical areas defined by the Urban Audit, a Eurostat initiative aimed at providing a full collection of statistical data dealing specifically with metropolitan regions all over Europe.

\subsection{Landscape Analysis}

The information used here was derived from Urban Atlas maps scaled 1:10,000 and produced on behalf of Land Copernicus initiative. Maps covered separately the metropolitan region of each city. All cities $>100,000$ inhabitants in Europe were assumed in the initiative and urban boundaries were defined according to Eurostat Urban Audit classification of metropolitan regions in Europe, considering commuting patterns derived from the latest population census and studied at municipal scale. Urban Atlas maps provide a consistent and homogeneous information base as far as coverage, temporal acquisition of the original data, spatial resolution, and classification system are concerned. The resulting land-use nomenclature was articulated into 20 classes (Table 1), including 16 urban classes and 4 non-urban classes, providing a comprehensive description of land-use in European metropolitan regions.

Table 1. List of landscape variables considered in this study (variables from CUF to SPORT: patch perimeter length by land-use class in total patch perimeter).

\begin{tabular}{ll}
\hline Variable's Name & Abbreviation \\
\hline Continuous Urban Fabric (S.L. $>$ 80\%) & CUF \\
Discontinuous Dense Urban Fabric (S.L.: $50-80 \%)$ & DDUF \\
\hline
\end{tabular}


Table 1. Cont.

\begin{tabular}{ll}
\hline Discontinuous Medium Density Urban Fabric (S.L.: 30-50\%) & DMDUF \\
Discontinuous Low Density Urban Fabric (S.L.: 10-30\%) & DLDUF \\
Discontinuous Very Low Density Urban Fabric (S.L. < 10\%) & DVLDUF \\
Industrial, commercial, public, military and private units & ICPMPU \\
Agricultural + Semi-natural areas + Wetlands & AGR \\
Isolated Structures & ISOL \\
Airports & AIRP \\
Construction sites & CON \\
Fast transit roads and associated land & FAST \\
Forests & FOR \\
Green urban areas & GREEN \\
Land without current use & LAND \\
Mineral extraction and dump sites & MINE \\
Other roads and associated lands & ROADS \\
Port areas & PORT \\
Railways and associated land & RAIL \\
Sports and leisure facilities & SPORT \\
Patch perimeter $(m)$ & P \\
Patch size (m ${ }^{2}$ ) & A \\
Perimeter to area ratio & P/A \\
Distance from downtown $(m)$ & Dist \\
Pielou J evenness index & J \\
\hline
\end{tabular}

\subsection{Spatial Analysis}

The statistical analysis was developed using patches as the elementary spatial unit. Urban and non-urban patches bordering each built-up patch were identified using ArcGIS (ESRI Inc., Redwoods, Redlands, CA, USA). A procedure based on "zonal statistics", "spatial analyst" and other ArcGIS "toolbox" commands was developed with the aim to determine the total perimeter of each built-up patch and the share of each surrounding land class in the total perimeter. The percent share of a given class perimeter in total patch perimeter was calculated for each patch classified according to the land-use nomenclature system reported in Section 2.2. Diversity in the landscape surrounding each built-up parcel was assessed by computation on the share of each land-use class perimeter in total patch perimeter (pi) using the Shannon index $\left(\mathrm{H}^{\prime}\right)$ calculated as

$$
H^{\prime}=-\sum_{n i=1} p_{i} \log p_{i}
$$

Five ancillary variables were finally calculated at the patch scale with the objective to assess the impact of the local context on the composition of landscape surrounding each urban parcel: (i) linear distance from downtown (calculated determining the centroid of each patch and deriving the linear distance with a central place in the city: Platia Syndagmatos in Athens, Piazza Barberini in Rome, Placa de Catalunia in Barcelona and Placa do Commercio in Lisbon); (ii) elevation (a binary variable distinguishing lowland patches labeled with " 0 " from hilly and mountain patches labeled with " 1 "); (iii) patch size (logarithm); (iv) perimeter-to-area ratio; and (v) percentage of sea coast bordering each patch, considering that all metropolitan regions investigated in this study include a (more or less extended) coastal district.

\subsection{Statistical Analysis}

Descriptive statistics were computed with the aim to provide an advanced knowledge of the spatial distribution of landscape patches in the four metropolitan regions, using scatter plots that illustrate the average location of patches by land-use class (computing on patch centroids) and the mean distance from the respective city centre (see Section 2.3). 
A Principal Component Analysis (PCA) was run on the matrix composed of land-use indicators resulting from the spatial analysis illustrated in Section 2.2, with the objective to identify factors influencing the composition and structure of landscape around each investigated patch. To avoid multi-collinearity, the share of "inland water" perimeter in total patch perimeter was considered as a supplementary variable in the PCA. As the PCA was based on the correlation matrix, components with eigenvalue $>1$ have been analyzed for loading structure. The Kaiser-Meyer-Olkin (KMO) measure of sampling adequacy, which tests whether the partial correlations among variables are small, and Bartlett's test of sphericity, which tests whether the correlation matrix is an identity matrix, have been used to assess the quality of PCA outputs. These tests to indicate whether the selected model is suited to analyze the original datasets. Statistical analysis was performed using Statistica 5.0 package (STAT software Inc., Tulsa, OK, USA).

Similarity in the spatial distribution of land-use classes bordering each patch was investigated using a two-way hierarchical clustering based on Euclidean distances and Ward's agglomeration rule and aggregating patches and indicators respectively on rows and columns. This analysis was aimed at identifying the interplay between the territorial context (e.g., topography, accessibility, urban gradient/human pressure) and landscape spatial structure based on the analysis of nearest neighboring land-use types. This examination can also improve further involvements dealing with the analysis of urban-rural gradient in interpreting land-use and land cover change (LUCC) [51-54].

After standardization of the input variables, a linear discriminant analysis was carried out separately for the 4 cities with the aim to discriminate spatial neighbor patterns for three basic classes of land-use (urban: code 1; agriculture: code 2; and forest and natural land: code 3) using the same variables considered as input in the PCA (see above). A forward stepwise approach was adopted to identify and rank the most significant predictors discriminating among the three land-use classes assumed above using a F-to enter $p$-value of 0.01 . To rank the importance of the different predictors identified by the stepwise procedure, results of each model were presented considering standardized coefficients and tests of significance (a F-statistic testing for the null-hypothesis of non-significant discriminant variable).

\section{Results}

\section{Basic Characteristics of Patches and Nearest Neighbor Landscape}

A statistical analysis of spatial distribution of landscape patches was proposed in Figure 1, outlining the average location of patches (centroid) by land-use class in each metropolitan region. In Lisbon, infrastructures (ports, roads, railways, and airports), together with isolated settlements, display a peripheral location. More central locations were found for agricultural areas and forests. On average, compact and moderately dispersed settlements display central or semi-central locations. Land-use structure in Barcelona reveals, on average, more concentrated patches relegating agricultural areas, forests and road network to more peripheral locations. Continuous settlements occupy, on average, central places and discontinuous settlements illustrate a semi-central distribution. In Rome, most peripheral locations are occupied by discontinuous, low-density residential settlements, isolated settlements, green areas including suburban parks, airports, ports and water bodies. Compact and more dispersed settlements, agricultural areas, forests and road network occupy central or semi-central locations. In Athens, land-use distribution was quite heterogeneous over space, with peripheral locations occupied by infrastructures, medium-low density residential settlements, isolated settlements, water bodies and forests. Compact and discontinuous dense residential settlements, service and industrial settlements and agricultural areas locate preferentially in central or semi-central places. 
Sustainability 2018, 10, 2147

6 of 17

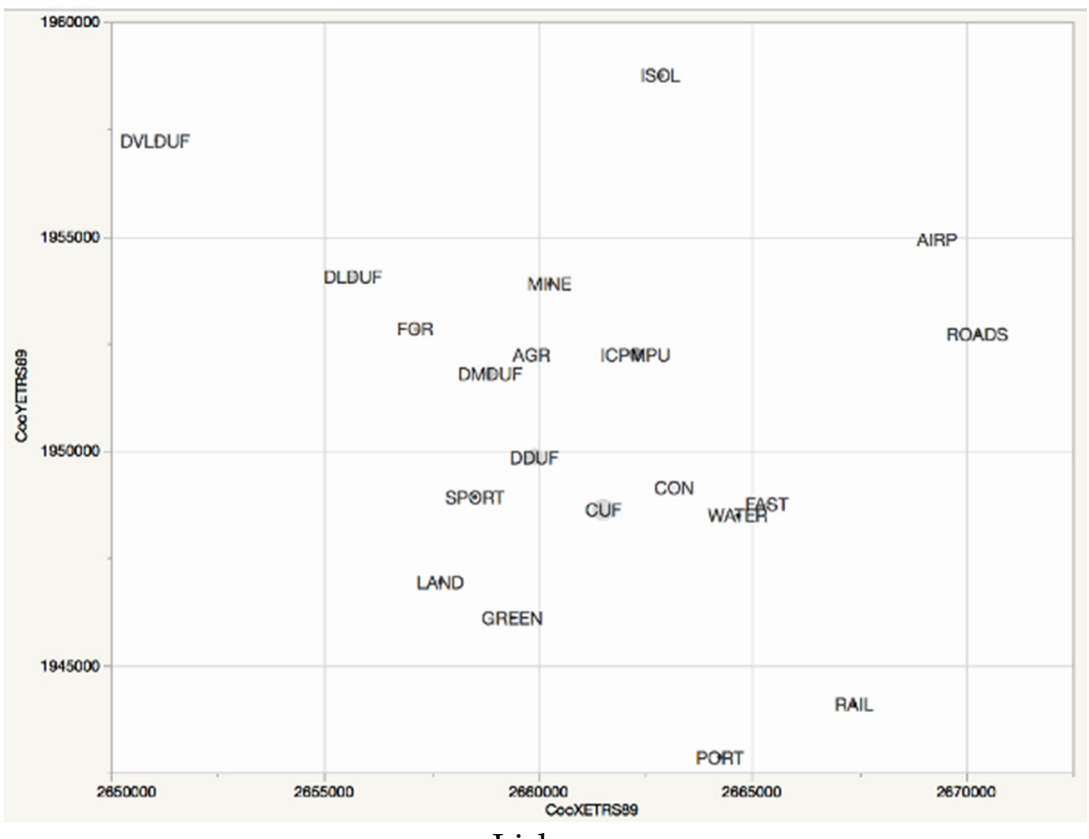

Lisbon

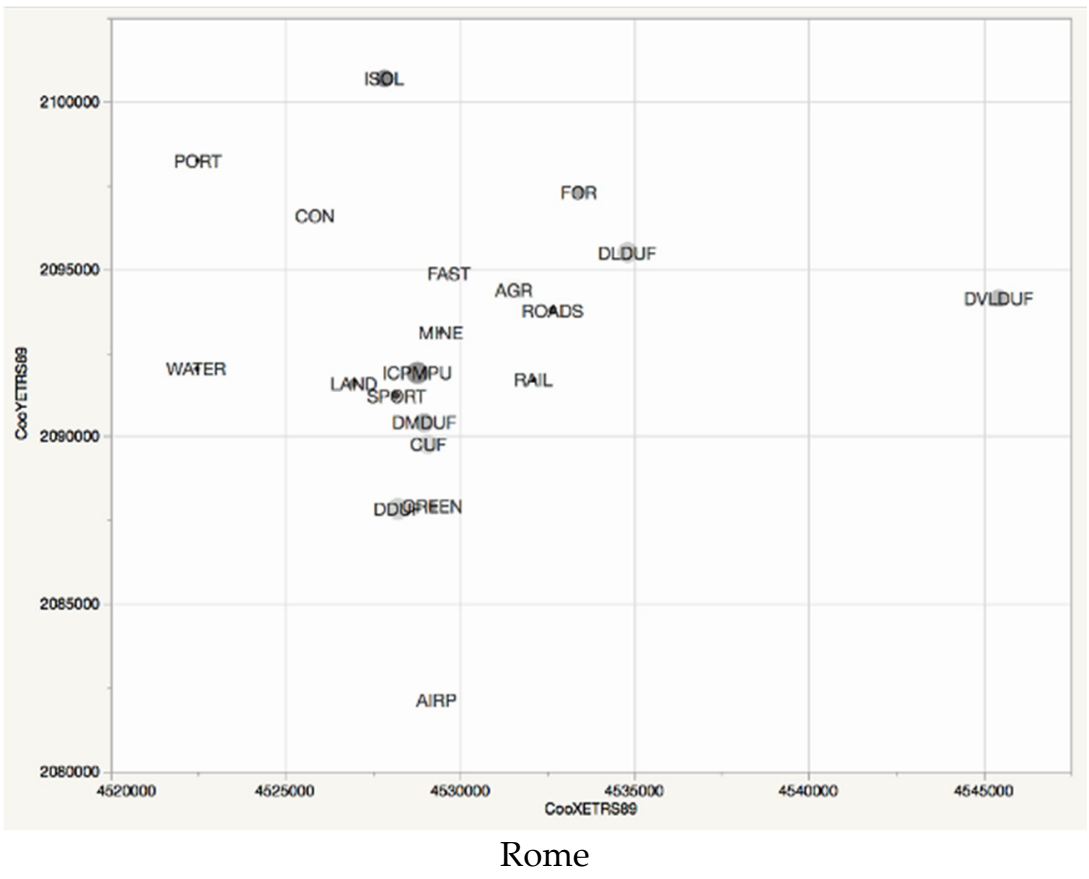

Figure 1. Cont. 

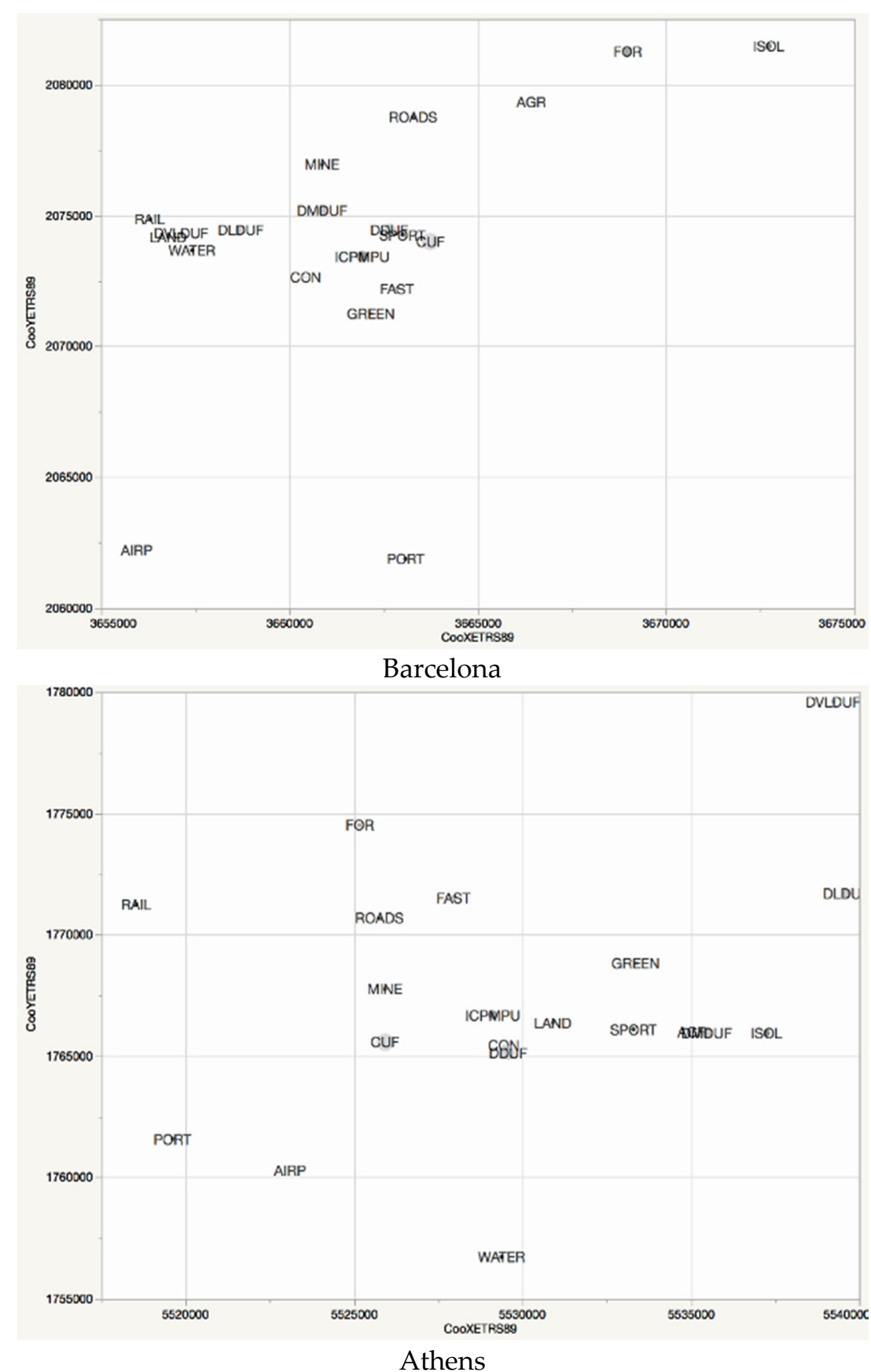

Figure 1. Spatial clustering of land-use classes in each metropolitan region.

A specific analysis of the spatial distribution of patches by land-use class and distance from downtown is reported in Figure 2. Land-use classes display, on average, a similar distribution along the urban gradient in all cities investigated, with a (more or less) evident variability possibly associated with place-specific factors. Compact urban fabric occupies central locations in Athens and semi-central locations in Barcelona, with Lisbon and Rome situating in-between. Variability along urban gradients is the highest in Barcelona and the lowest in Athens. Patches of dispersed, medium-low density residential urban fabric are situated relatively close to the inner city of Lisbon and more distant in Athens, Barcelona and Rome, with increasing variability and specific spatial patterns for medium-density and low-density settlements observed in Barcelona and Rome: as expected, medium-density settlements grew at lower distances from downtown than low-density settlements in 
these cities. Industrial, commercial and residential settlements define a very high spatial heterogeneity in all cities. Agricultural and forest patches display a substantially homogeneous spatial distribution in Rome and Lisbon, with average distance from downtown ranging between 10 and $20 \mathrm{~km}$ and a more heterogeneous pattern in Barcelona and Athens.

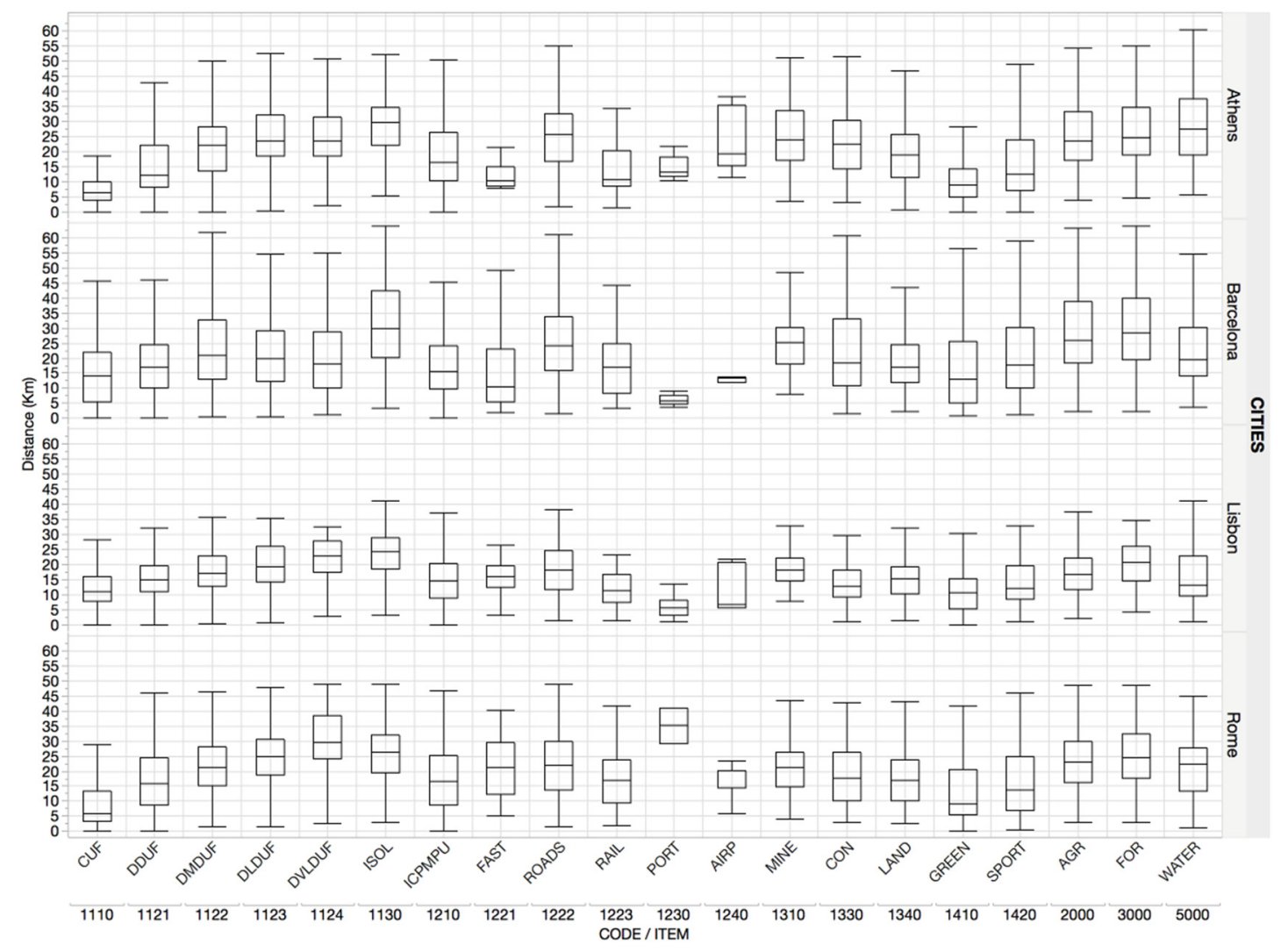

Figure 2. Distance of patches from the inner city by land-use class and metropolitan region.

Results of a principal component analysis run on landscape indicators (patch perimeters and ancillary variables) indicate a substantial similarity in landscape patterns across metropolitan regions, with local specificities depending on certain associations among land-use types (Figure 3). The four principal components were extracted and compared among cities. In Lisbon, components 1-4 accounted for nearly $20 \%$ of cumulated variance, a relevant finding considering the high number of input variables. Components identify spatial gradients characterized by land-use polarizations in: (i) compact urban fabric, non-residential urban fabric, agricultural land and infrastructure (component 1 vs. 2); (ii) low-density urban fabric and road infrastructure (component 1 vs. 3); and (iii) agricultural land and isolated buildings (component 1 vs. 4). In Barcelona, components 1-4 accounted for nearly $19 \%$ of cumulated variance and identify a more polarized spatial distribution of compact urban fabric, natural areas (including agricultural land and forests), road network and isolated buildings in respect with other land-use classes. In Rome, a cumulated variance of $19 \%$ was explained by components $1-4$, evidencing spatial polarizations between: (i) agricultural land and discontinuous dense residential urban fabric; and (ii) compact urban fabric and isolated buildings. Moreover, patches devoted to agricultural have a very low perimeter-to-area ratio. In Athens, the first four components explain together more than $20 \%$ of the total matrix variance. Compact urban fabric and distance from downtown assume very high loadings on components 1 and 2, as expected in a monocentric region, evidencing a spatial gradient distinguishing residential urban fabric from agricultural areas. Road network and isolated buildings reveal together a spatial distribution diverging from typical locations of cropland. 


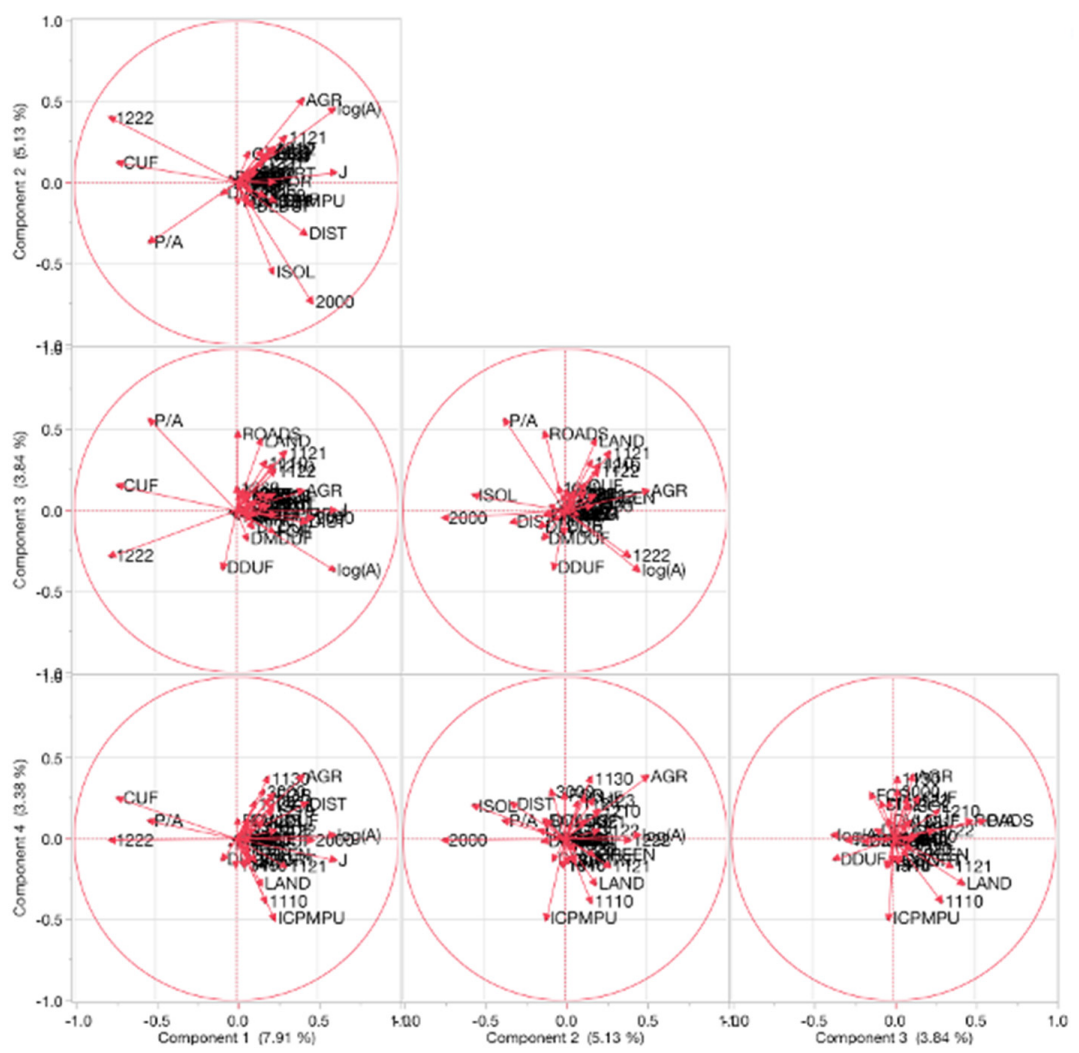

Lisbon

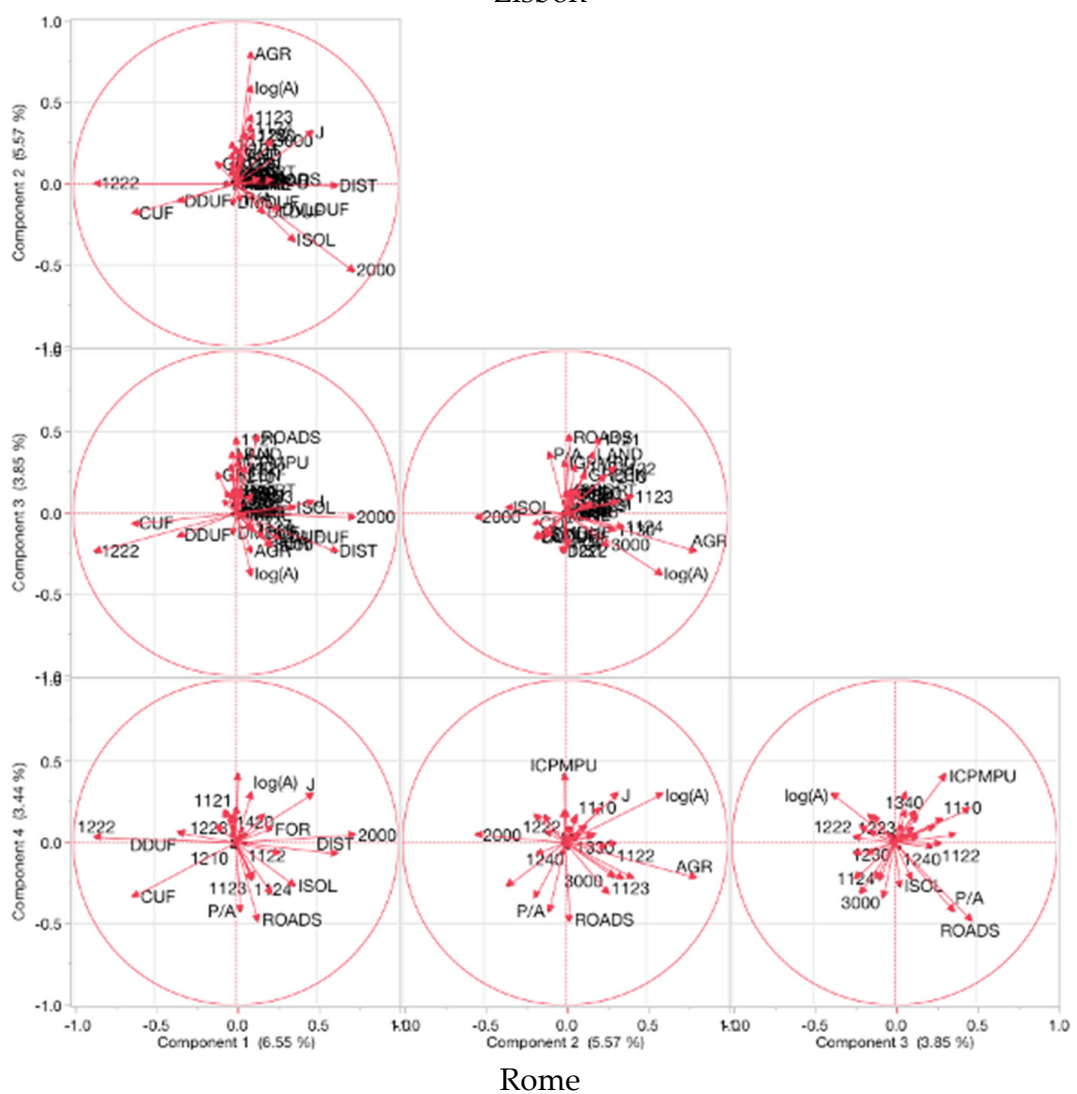

Figure 3. Cont. 

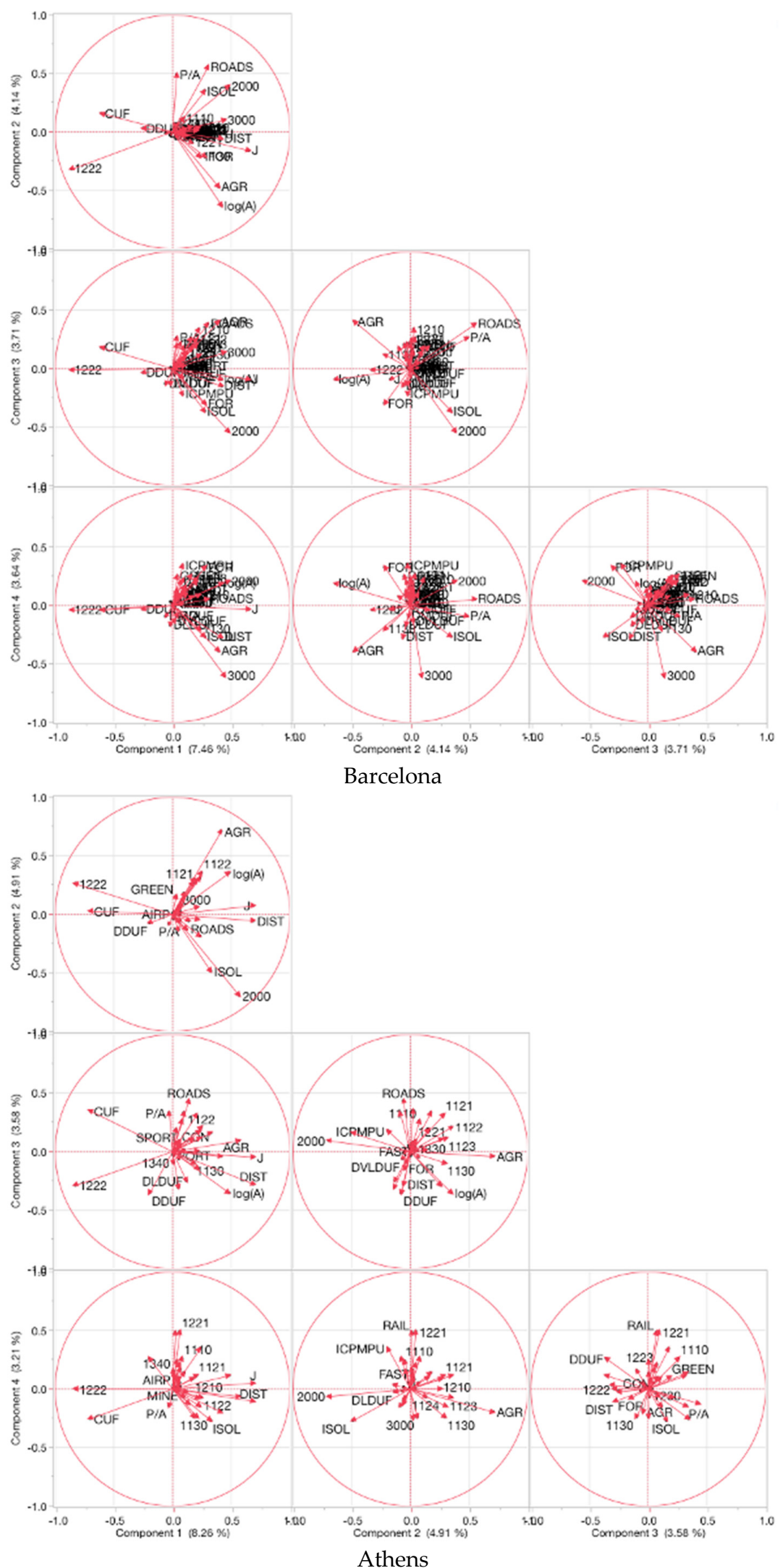

Figure 3. Biplot of principal component analysis in the four metropolitan regions. 
Hierarchical clustering explored similarities in the spatial structure of land-use surrounding landscape patches in the metropolitan regions (Figure 4). Four clusters were identified in Lisbon, distinguishing: (i) linear infrastructures with a specific patch perimeter-to-area ratio; from (ii) agricultural patches far from the inner city; (iii) forest land, water bodies, urban parks, land waiting for construction and non-residential urban fabric; and (iv) residential urban fabric, both compact and dispersed. In Barcelona, tree clusters were identified, outlining similarities between: (i) low-density residential urban fabric and linear infrastructures (from 1122 to 1222); and (ii) natural land (agriculture + forest) and very low-density, discontinuous urban fabric (from code 2 to 3000). The largest cluster (iii) includes compact and semi-dense settlements, non-residential urban settlements, infrastructures and water bodies. In Rome, hierarchical clustering indicates three homogeneous groups: (i) discontinuous, low-density residential urban fabric and forest land (from Code 2 to 3000); (ii) agricultural land patches at increasingly high distances from downtown; and (iii) the remaining variables including infrastructures, compact and semi-dense urban fabric, urban parks, land waiting for building and water bodies. Finally, Athens' spatial structure was characterized by two main clusters: (i) low-density residential urban fabric, forests and agricultural land; and (ii) compact urban fabric, other urban land-use, water bodies, infrastructures and urban parks.
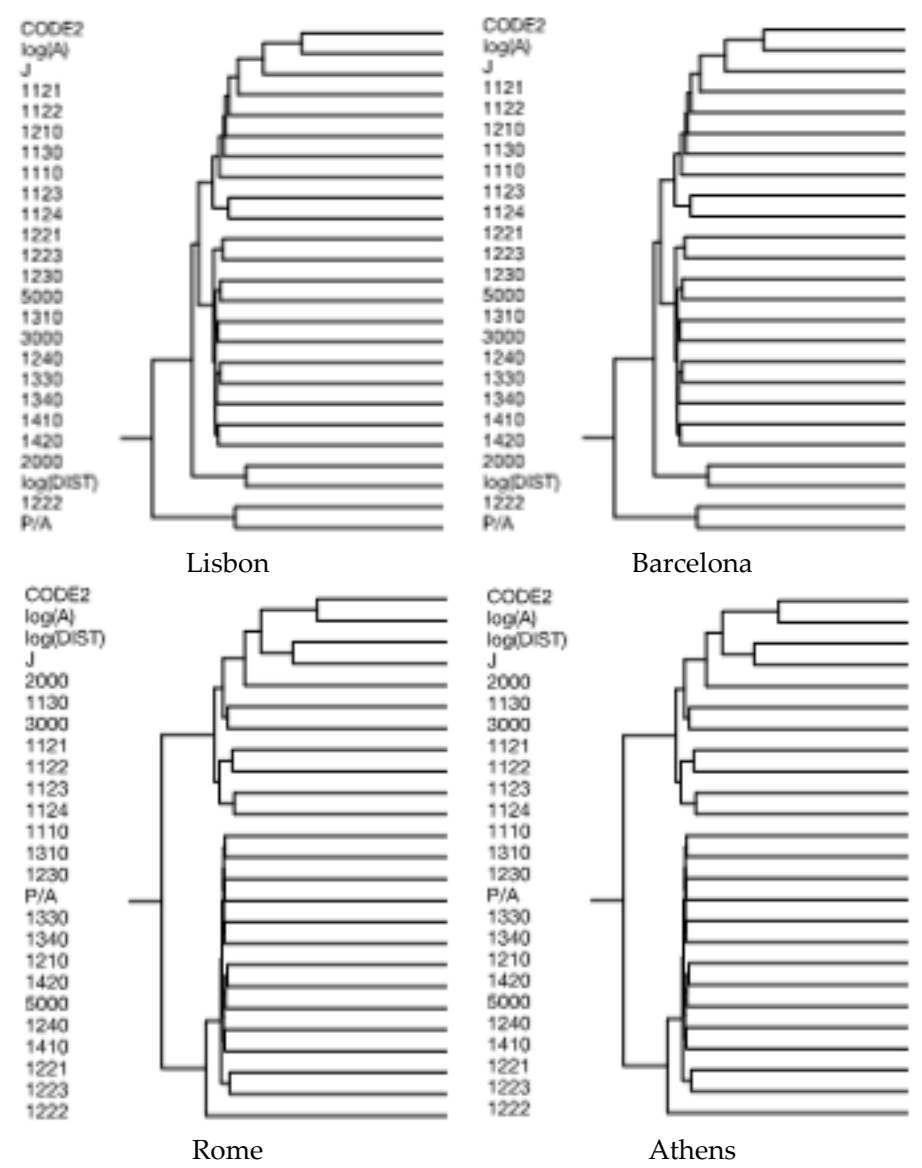

Figure 4. Hierarchical clustering of landscape and patch attributes in the four metropolitan regions (Code2 indicates a dummy for elevation, see Section 2.3).

A step-wise discriminant analysis was finally carried out with the aim to identify the land-use structure discriminating urban, agricultural and forest patches (Table 2) separately for each city. In Lisbon, the most relevant land-use classes identifying the nearest neighbor landscape structure of urban, agricultural and forest patches are: discontinuous residential urban fabric, non-residential urban fabric, linear infrastructures, urban parks, cropland and water bodies. A rather different 
context was observed in Barcelona, with the most relevant variables being compact urban fabric, linear infrastructures, urban parks, cropland and water bodies, indicating substantial differences in the urban structure of the two regions, more compact in Barcelona and relatively more dispersed in Lisbon. In Rome, most variables contribute significantly to discriminate urban from agricultural and forest patches, which indicate a very heterogeneous spatial structure, with no specific neighboring patterns. In Athens, residential urban areas (both compact and dispersed) are the most relevant variables discriminating among patch types, together with land waiting for building, urban parks and, to a lesser extent, cropland.

Table 2. Results of a step-wise linear discriminant analysis ranking variables according to their importance in the identification of patches with urban (code 1), agricultural (code 2) or forest (code 3) use by city (only significant F-to enter at $p<0.001$ were shown).

\begin{tabular}{ccccc}
\hline Variable & Lisbon & Barcelona & Rome & Athens \\
\hline 1110 & & 229 & 218 & 114 \\
1121 & 508 & & 52 & 695 \\
1122 & 538 & & 196 & 1549 \\
1123 & 568 & & 1053 & 1297 \\
1124 & & & 1802 & 304 \\
1130 & 1625 & 2290 & 2764 & 7148 \\
1210 & 496 & 77 & & 555 \\
1221 & 403 & 81 & 185 & \\
1222 & 638 & 5476 & 1345 & 5021 \\
1310 & 148 & & 90 & 132 \\
1330 & & & 105 & \\
1340 & 329 & 386 & 652 & 1269 \\
1410 & 215 & 622 & 847 & 2069 \\
1420 & & & & 101 \\
2000 & 1045 & 5252 & 2639 & 6627 \\
3000 & & & 108 & \\
5000 & 250 & 308 & 115 & \\
\hline
\end{tabular}

\section{Discussion}

The present study introduces an original analysis investigating together landscape composition and land-use spatial structure. Each patch forming the investigated landscape was examined along its perimeter and its neighboring urban and non-urban areas, defining a specific landscape configuration in each city $[55,56]$. The theory of contact and the analysis of the adjacent mosaic proved to be fundamental to assess the degree of fragmentation or homogenization in a given landscape. Under specific assumptions and case studies, the proposed methodology assessed complexity of fringe landscapes [57]. This approach is considered as complementary to classical landscape metrics and proved to be particularly useful to characterize complex, fragmented landscapes profiling metropolitan regions based an integrated evaluation of their structural (landscape) and functional (land-use) organization.

Using patch-level data based on perimeter metrics, various processes of landscape transformation can be identified and described comprehensively [58]. Results of the multivariate analysis run to characterize distinctive spatial patterns of the selected patch perimeter metrics identify different morphological configurations in the four metropolitan regions, suggesting that the metric's ensemble adopted in this study is suitable to represent typical regional-scale landscape structures in a range of metropolitan configurations, from compact, polycentric cities (Barcelona) to dispersed, monocentric cities (Lisbon). Interestingly, perimeter metrics assumed different values for each investigated land-use class, with peculiar characteristics associated to each city. For instance, land-use types assessing residential, discontinuous urban patches were associated to particularly high values of perimeter metrics, indicating place-specific patch fragmentation, a spatially-associated distribution of land-use types and a landscape complexity profile specific for each examined region. 
In this regard, multivariate analysis indicates substantial differences among cities, reflecting the range of morphological configurations described above (from compact monocentric to dispersed polycentric) and suggesting that urban expansion is accompanied with multiple modifications in the use of the surrounding non-urban land. The computational approach proposed in this study and based on spatially-explicit metrics of landscape configuration and proximity reflects latent changes in local socio-environmental structures [59], suggesting that scattered urban expansion may determine a latent polarization in suburban areas with highly fragmented and more homogeneous landscapes [60,61], respectively, associated with mixed cropland and forest systems [10].

Place-specific contexts shaping the landscape structure that surrounds each studied patch were considered together with landscape-specific factors (e.g., patch size and shape, elevation, distance from the sea coast). Spatial variability in the physical boundaries among patches (indicating the nearest neighboring land-use spatial regime for each patch) is likely reflective of socio-spatial, demographic and economic evolutions that require specific investigation starting from the simplified results of the landscape analysis [4,62]. For example, in compact cities (Athens, and, to a lesser extent, Barcelona), a higher proportion of natural land surrounding urban settlements during compact growth was associated with larger urban patches, while cropland increased at lower elevation and dominated non-urban landscapes around fringe settlements. The role of factors such as the distance from inner cities in shaping the structure of suburban landscapes is largely variable across cities-because of the different spatial organization of each metropolitan region—and the reverse pattern was observed for urban patch size.

Approaches based on patch perimeter metrics allow investigating together to form and functions of urban vs. rural landscapes, representing effective tools that integrate practical knowledge based on high-resolution maps with a computational procedure following spatial analysis principles, under cross-section surveys or measurements repeated over time. A multivariate analysis of patch perimeter metrics may identify-better than other, more traditional, landscape ecology techniques—the latent interplay between landscape and local communities (demography, socio-spatial organization, and economic structure) resulting in a specific profile of land-use configuration at each city [59]. Changes in the spatial structure of peri-urban landscape are demonstrated to have implications concerning sustainable development and land management of fringe land [58,63-67]. Comparative investigation of metropolitan evolution based on spatiotemporal trends in neighboring patches' structure and other morphological features of landscapes proved to be consistent information when designing policies aimed at sustainable land management and urban control [55,68]. In these regards, policies integrating spatial planning and developmental measures can influence specific form-function relationships characterizing contemporary cities and their landscape [24]. The base of knowledge derived from empirical results of the proposed analysis at both patch and landscape scales are pertinent from both the positive and normative viewpoints, enlightening planning decisions and advancing ecological and social disciplines $[55,63]$.

\section{Conclusions}

A comprehensive investigation of spatial structures, such as those characterizing land-use, is particularly important to provide a comprehensive overview of evolving landscapes and land-use changes at both metropolitan and local scale $[58,69]$. Based on the perimeter of each patch, the surrounding patches having a spatial contact with it express a specific landscape mosaic [29], reflecting (apparent and latent) relationships among land-use and outlining intrinsic processes such as urbanization, land consumption, non-urban land abandonment, and forestation $[2,5,7,10,56,70]$, among others. Such knowledge is a base to a sustainable development agenda for European countries. Newly emerging landscape forms, better detected using innovative approaches as the example provided in this study, require an original analysis of land-use relationships, pointing out the significance of an enduring assessment of landscape alterations, and then supporting and orienting convenient conservation policies $[12,22,26,71]$. Comparative analysis is particularly 
suited to clarify the socio-environmental consequences of land-use transformations and landscape fragmentation in ecologically-fragile and socially-divided European metropolitan regions under increasing anthropogenic pressure, with the aim of achieving a sustainable model of urban growth [72], more effective planning policies and strategies encouraging a land-saving economic development.

Author Contributions: I.Z. and S.P. conceived and designed the analytical framework; C.F. and V.B. analyzed the data; and L.S. and P.S. wrote the paper.

Funding: This research received no external funding.

Acknowledgments: Part of this study was realized in the framework of the SAUS “Environmental sustainability and land-use" initiative financed to CREA by the administrative regional authority of Latium, Italy.

Conflicts of Interest: The authors declare no conflict of interest.

\section{References}

1. Antrop, M. Landscape change and the urbanization process in Europe. Landsc. Urban Plan. 2004, 67, 9-26. [CrossRef]

2. Ferrara, A.; Salvati, L.; Sateriano, A.; Carlucci, M.; Gitas, I.; Biasi, R. Unraveling the 'stable' landscape: A multi-factor analysis of unchanged agricultural and forest land (1987-2007) in a rapidly-expanding urban region. Urban Ecosyst. 2016, 19, 835-848. [CrossRef]

3. Bhatta, B.; Saraswati, S.; Bandyopadhyay, D. Quantifying the degree-of-freedom, degree-of-sprawl, and degree-of-goodness of urban growth from remote sensing data. Appl. Geogr. 2010, 30, 96-111. [CrossRef]

4. Pili, S.; Grigoriadis, E.; Carlucci, M.; Clemente, M.; Salvati, L. Towards Sustainable Growth? A Multi-criteria Assessment of (Changing) Urban Forms. Ecol. Indic. 2017, 76, 71-80. [CrossRef]

5. Radeloff, V.C.; Hammer, R.B.; Stewart, S.I. Rural and suburban sprawl in the US Midwest from 1940 to 2000 and its relation to forest fragmentation. Conserv. Biol. 2005, 19, 793-805. [CrossRef]

6. Serra, P.; Pons, X.; Saurí, D. Land-cover and land-use change in a Mediterranean landscape: A spatial analysis of driving forces integrating biophysical and human factors. Appl. Geogr. 2008, 28, 189-209. [CrossRef]

7. Shrestha, M.K.; York, A.M.; Boone, C.G.; Zhang, S. Land fragmentation due to rapid urbanization in the Phoenix Metropolitan Area: Analyzing the spatiotemporal patterns and drivers. Appl. Geogr. 2012, 32, 522-531. [CrossRef]

8. Duvernoy, I.; Zambon, I.; Sateriano, A.; Salvati, L. Pictures from the other side of the fringe: Urban growth and peri-urban agriculture in a post-industrial city (Toulouse, France). J. Rural Stud. 2018, 57, 25-35. [CrossRef]

9. Allen, A. Environmental planning and management of the peri-urban interface: Perspectives on an Emerging field. Environ. Urban. 2003, 15, 135-147. [CrossRef]

10. Colantoni, A.; Mavrakis, A.; Sorgi, T.; Salvati, L. Towards a 'polycentric' landscape? Reconnecting fragments into an integrated network of coastal forests in Rome. Rend. Lincei 2015, 26, 615-624. [CrossRef]

11. Kroeger, T.; Casey, F. An assessment of market-based approaches to providing ecosystem services on agricultural lands. Ecol. Econ. 2007, 64, 321-332. [CrossRef]

12. Simmons, C.; Walker, R.; Perz, S.; Arima, E.; Aldrich, S.; Caldas, M. Spatial patterns of frontier settlement: Balancing conservation and development. J. Lat. Am. Geogr. 2016, 15, 33-58. [CrossRef]

13. Biasi, R.; Brunori, E.; Ferrara, C.; Salvati, L. Towards sustainable rural landscapes? a multivariate analysis of the structure of traditional tree cropping systems along a human pressure gradient in a Mediterranean region. Agroforest. Syst. 2017, 91, 1199-1217. [CrossRef]

14. Christopoulou, O.; Polyzos, S.; Minetos, D. Peri-urban and urban forests in Greece: Obstacle or advantage to urban development? J. Environ. Manag. 2007, 18, 382-395. [CrossRef]

15. Feranec, J.; Jaffrain, G.; Soukup, T.; Hazeu, G. Determining changes and flows in European landscapes 1990-2000 using CORINE land cover data. Appl. Geogr. 2010, 30, 19-35. [CrossRef]

16. Frondoni, R.; Mollo, B.; Capotorti, G. A landscape analysis of land cover change in the Municipality of Rome (Italy), Spatio-temporal characteristics and ecological implications of land cover transitions from 1954 to 2001. Landsc. Urban Plan. 2011, 100, 117-128. [CrossRef]

17. Cecchini, M.; Zambon, I.; Pontrandolfi, A.; Turco, R.; Colantoni, A.; Mavrakis, A.; Salvati, L. Urban sprawl and the 'olive' landscape: Sustainable land management for 'crisis' cities. GeoJournal 2018, 1-19. [CrossRef] 
18. Salvati, L.; Sateriano, A.; Grigoriadis, E.; Carlucci, M. New wine in old bottles: The (changing) socioeconomic attributes of sprawl during building boom and stagnation. Ecol. Econ. 2017, 131, 361-372. [CrossRef]

19. Zambon, I.; Benedetti, A.; Ferrara, C.; Salvati, L. Soil Matters? A Multivariate Analysis of Socioeconomic Constraints to Urban Expansion in Mediterranean Europe. Ecol. Econ. 2018, 146, 173-183. [CrossRef]

20. Franks, J. Boundary organizations for sustainable land management: The example of Dutch Environmental Co-operatives. Ecol. Econ. 2010, 70, 283-295. [CrossRef]

21. Zambon, I.; Serra, P.; Sauri, D.; Carlucci, M.; Salvati, L. Beyond the 'Mediterranean city': Socioeconomic disparities and urban sprawl in three Southern European cities. Geogr. Ann. Ser. B Hum. Geogr. 2017, 99, 319-337. [CrossRef]

22. Agnoletti, M. Rural landscape, nature conservation and culture: Some notes on research trends and management approaches from a (southern) European perspective. Landsc. Urban Plan. 2014, 126, 66-73. [CrossRef]

23. Kasanko, M.; Barredo, J.I.; Lavalle, C.; McCormick, N.; Demicheli, L.; Sagris, V.; Brezger, A. Are European Cities Becoming Dispersed? A Comparative Analysis of Fifteen European Urban Areas. Landsc. Urban Plan. 2006, 77, 111-130. [CrossRef]

24. Longhi, C.; Musolesi, A. European cities in the process of economic integration: Towards structural convergence. Ann. Reg. Sci. 2007, 41, 333-351. [CrossRef]

25. Turok, I.; Mykhnenko, V. The trajectories of European cities, 1960-2005. Cities 2007, 24, 165-182. [CrossRef]

26. Schonewald-Cox, C.M.; Bayless, J.W. The boundary model: A geographical analysis of design and conservation of nature reserves. Biol. Conserv. 1986, 38, 305-322. [CrossRef]

27. Banerjee, S.; Carlin, B.P.; Gelfand, A.E. Hierarchical Modeling and Analysis for Spatial Data; Crc Press: Boca Raton, FL, USA, 2014.

28. Allmendinger, P.; Haughton, G. Soft spaces, fuzzy boundaries, and metagovernance: The new spatial planning in the Thames Gateway. Environ. Plan. A 2009, 41, 617-633. [CrossRef]

29. Forman, R.T. Land Mosaics: The Ecology of Landscapes and Regions; Island Press: Washington, DC, USA, 2014.

30. Blumer, H. Race prejudice as a sense of group position. Pac. Sociol. Rev. 1958, 1, 3-7. [CrossRef]

31. Jackman, M.R.; Crane, M. "Some of my best friends are black ... ": Interracial friendship and whites' racial attitudes. Public Opin. Q. 1986, 50, 459-486. [CrossRef]

32. Jacobs, J. The Death and Life of Great American Cities; Random House: New York, NY, USA, 1961.

33. Schmid, K.; Hewstone, M.; Hughes, J.; Jenkins, R.; Cairns, E. Residential segregation and intergroup contact: Consequences for intergroup relations, social capital and social identity. In Theorizing Identities and Social Action; Palgrave Macmillan: London, UK, 2009; pp. 177-197.

34. Wessel, T. Does diversity in urban space enhance intergroup contact and tolerance? Geogr. Ann. Ser. B Hum. Geogr. 2009, 91, 5-17. [CrossRef]

35. Opdam, P.F.M.; Westerink, J.; Vos, C.C.; Vries, E.A.D. The role and evolution of boundary concepts in transdisciplinary landscape planning. Plan. Theory Pract. 2015, 16, 63-78. [CrossRef]

36. Westerink, J.; Opdam, P.; Van Rooij, S.; Steingröver, E. Landscape services as boundary concept in landscape governance: Building social capital in collaboration and adapting the landscape. Land Use Policy 2017, 60, 408-418. [CrossRef]

37. Cao, K.; Huang, B.; Wang, S.; Lin, H. Sustainable land use optimization using Boundary-based Fast Genetic Algorithm. Comput. Environ. Urban Syst. 2015, 36, 257-269. [CrossRef]

38. Hassan, M.M. Monitoring land use/land cover change, urban growth dynamics and landscape pattern analysis in five fastest urbanized cities in Bangladesh. Remote Sens. Appl. Soc. Environ. 2017, 7, 69-83. [CrossRef]

39. Herold, M.; Liu, X.; Clarke, K.C. Spatial metrics and image texture for mapping urban land use. Photogramm. Eng. Remote Sens. 2003, 69, 991-1001. [CrossRef]

40. Riitters, K.H.; O'neill, R.V.; Hunsaker, C.T.; Wickham, J.D.; Yankee, D.H.; Timmins, S.P.; Jackson, B.L. A factor analysis of landscape pattern and structure metrics. Landsc. Ecol. 1995, 10, 23-39. [CrossRef]

41. Batty, M.; Longley, P.A. The morphology of urban land use. Environ. Plan. B Plan. Des. 1988, 15, 461-488. [CrossRef]

42. White, R.; Engelen, G. Cellular automata and fractal urban form: A cellular modelling approach to the evolution of urban land-use patterns. Environ. Plan. A 1993, 25, 1175-1199. [CrossRef] 
43. Christiansen, T.; Jorgensen, K.E. Transnational governance 'above' and 'below' the state: The changing nature of borders in the New Europe. Reg. Fed. Stud. 2000, 10, 62-77. [CrossRef]

44. Gregory, I.N. Time-variant GIS databases of changing historical administrative boundaries: A European comparison. Trans. GIS 2002, 6, 161-178. [CrossRef]

45. Jacquez, G.M.; Maruca, S.; Fortin, M.J. From fields to objects: A review of geographic boundary analysis. J. Geogr. Seymss 2000, 2, 221-241. [CrossRef]

46. Westerink, J.; Kempenaar, A.; Van Lierop, M.; Groot, S.; Van der Valk, A.; Van den Brink, A. The participating government: Shifting boundaries in collaborative spatial planning of urban regions. Environ. Plan. C Govern. Policy 2017, 35, 147-168. [CrossRef]

47. Jones, R. Categories, borders and boundaries. Prog. Hum. Geogr. 2009, 33, 174-189. [CrossRef]

48. Newman, D.; Paasi, A. Fences and neighbours in the postmodern world: Boundary narratives in political geography. Prog. Hum. Geogr. 1998, 22, 186-207. [CrossRef]

49. Machlis, G.E.; Tichnell, D.L. The State of the World's Parks; Westview Press: Boulder, CO, USA, 1985.

50. European Environment Agency. Mapping Guide for a European Urban Atlas; European Environment Agency: Copenhagen, Denmark, 2010.

51. McDonnell, M.J.; Hahs, A.K. The use of gradient analysis studies in advancing our understanding of the ecology of urbanizing landscapes: Current status and future directions. Landsc. Ecol. 2008, 23, 1143-1155. [CrossRef]

52. Modica, G.; Vizzari, M.; Pollino, M.; Fichera, C.R.; Zoccali, P.; Di Fazio, S. Spatio-temporal analysis of the urban-rural gradient structure: An application in a Mediterranean mountainous landscape (Serra San Bruno, Italy). Earth Syst. Dyn. 2012, 3, 263-279. [CrossRef]

53. Yang, Y.; Zhou, Q.; Gong, J.; Wang, Y. Gradient analysis of landscape spatial and temporal pattern changes in Beijing metropolitan area. Sci. China Technol. Sci. 2010, 53, 91-98. [CrossRef]

54. Salvati, L.; Carlucci, M. The economic and environmental performances of rural districts in Italy: Are 405 competitiveness and sustainability compatible targets? Ecol. Econ. 2011, 70, 2446-2453. [CrossRef]

55. Colantoni, A.; Grigoriadis, E.; Sateriano, A.; Venanzoni, G.; Salvati, L. Cities as selective land predators? A Lesson on Urban Growth, (Un)effective planning and Sprawl Containment. Sci. Total Environ. 2016, 545-546, 329-339. [CrossRef] [PubMed]

56. Munafò, M.; Salvati, L.; Zitti, M. Estimating soil sealing rate at national level-Italy as a case study. Ecol. Indic. 2013, 26, 137-140. [CrossRef]

57. Frenkel, A. The potential effect of national growth-management policy on urban sprawl and the depletion of open spaces and farmland. Land-Use Policy 2004, 21, 357-369. [CrossRef]

58. Carrion-Flores, C.; Irwin, E.G. Determinants of residential land-use conversion and sprawl at the rural-urban fringe. Am. J. Agric. Econ. 2004, 86, 889-904. [CrossRef]

59. Salvati, L.; Morelli, V.G.; Rontos, K.; Sabbi, A. Latent exurban development: City expansion along the rural-to-urban gradient in growing and declining regions of southern Europe. Urban Geogr. 2013, 34, 376-394. [CrossRef]

60. Carlucci, M.; Grigoriadis, E.; Rontos, K.; Salvati, L. Revisiting a Hegemonic Concept: Long-term 'Mediterranean Urbanization' in Between City Re-polarization and Metropolitan Decline. Appl. Spat. Anal. Policy 2017, 10, 347-362. [CrossRef]

61. Cuadrado-Ciuraneta, S.; Durà-Guimerà, A.; Salvati, L. Not only tourism: Unravelling suburbanization, second-home expansion and "rural" sprawl in Catalonia, Spain. Urban Geogr. 2017, 38, 66-89. [CrossRef]

62. Salvati, L.; Gargiulo Morelli, V. Unveiling Urban Sprawl in the Mediterranean Region: Towards a Latent Urban Transformation? Int. J. Urban Reg. Res. 2014, 38, 1935-1953. [CrossRef]

63. Salvati, L. Agro-forest Landscape and the 'Fringe' City: A Multivariate Assessment of Land-use Changes in a Sprawling Region and Implications for Planning. Sci. Total Environ. 2014, 490, 715-723. [CrossRef] [PubMed]

64. Zambon, I.; Colantoni, A.; Carlucci, M.; Morrow, N.; Sateriano, A.; Salvati, L. Land quality, sustainable development and environmental degradation in agricultural districts: A computational approach based on entropy indexes. Environ. Impact Assess. Rev. 2017, 64, 37-46. [CrossRef]

65. Monarca, D.; Cecchini, M.; Guerrieri, M.; Colantoni, A. Conventional and alternative use of biomasses derived by hazelnut cultivation and processing. VII Int. Congr. Hazelnut 2008, 845, 627-634. [CrossRef] 
66. Colantoni, A.; Delfanti, L.; Recanatesi, F.; Tolli, M.; Lord, R. Land use planning for utilizing biomass residues in Tuscia Romana (central Italy): Preliminary results of a multi criteria analysis to create an agro-energy district. Land Use Policy 2016, 50, 125-133. [CrossRef]

67. Zambon, I.; Sabbi, A.; Schuetze, T.; Salvati, L. Exploring forest 'fringescapes': Urban growth, society and swimming pools as a sprawl landmark in coastal Rome. Rend. Lincei 2015, 26, 159-168. [CrossRef]

68. Marraccini, E.; Debolini, M.; Moulery, M.; Abrantes, P.; Bouchier, A.; Chéry, J.P.; Napoleone, C. Common features and different trajectories of land cover changes in six Western Mediterranean urban regions. Appl. Geogr. 2015, 62, 347-356. [CrossRef]

69. Mallinis, G.; Koutsias, N.; Arianoutsou, M. Monitoring land-use/land cover transformations from 1945 to 2007 in two peri-urban mountainous areas of Athens metropolitan area, Greece. Sci. Total Environ. 2014, 490, 262-278. [CrossRef] [PubMed]

70. Ferrara, A.; Salvati, L.; Sabbi, A.; Colantoni, A. Urbanization, Soil Quality and Rural Areas: Towards a Spatial Mismatch? Sci. Total Environ. 2014, 478, 116-122. [CrossRef] [PubMed]

71. Laidley, T. Measuring Sprawl. A New Index, Recent Trends, and Future Research. Urban Aff. Rev. 2015. [CrossRef]

72. Grekousis, G.; Manetos, P.; Photis, Y.N. Modeling urban evolution using neural networks, fuzzy logic and GIS: The case of the Athens metropolitan area. Cities 2013, 30, 193-203. [CrossRef]

(C) 2018 by the authors. Licensee MDPI, Basel, Switzerland. This article is an open access article distributed under the terms and conditions of the Creative Commons Attribution (CC BY) license (http://creativecommons.org/licenses/by/4.0/). 